\title{
Corrigendum: Circular RNAs in Cancer - Lessons Learned From microRNAs
}

\author{
Mihnea Dragomir ${ }^{1,2,3}$ and George A. Calin ${ }^{1,4 *}$ \\ ${ }^{1}$ Department of Experimental Therapeutics, The University of Texas MD Anderson Cancer Center, Houston, TX, \\ United States, ${ }^{2}$ Research Center for Functional Genomics, Biomedicine and Translational Medicine, luliu Hatieganu \\ University of Medicine and Pharmacy, Cluj-Napoca, Romania, ${ }^{3}$ Department of Surgery, Fundeni Clinical Hospital, Carol Davila \\ University of Medicine and Pharmacy, Bucharest, Romania, ${ }^{4}$ Center for RNA Interference and Non-Coding RNAs, The \\ University of Texas MD Anderson Cancer Center, Houston, TX, United States
}

Keywords: circular RNA, microRNA, non-coding RNAs, cancer, biomarker

OPEN ACCESS

Approved by: Frontiers in Oncology Editorial Office,

Frontiers Media SA, Switzerland

${ }^{\star}$ Correspondence:

George A. Calin gcalin@mdanderson.org

Specialty section

This article was submitted to Cancer Molecular Targets and

Therapeutics,

a section of the journal

Frontiers in Oncology

Received: 19 July 2018

Accepted: 20 July 2018

Published: 21 September 2018

Citation:

Dragomir M and Calin GA (2018) Corrigendum: Circular RNAs in Cancer - Lessons Learned From microRNAs. Front. Oncol. 8:307. doi: 10.3389/fonc.2018.00307

\section{A corrigendum on}

Circular RNAs in Cancer - Lessons Learned From microRNAs

by Dragomir, M., and Calin, G. A. (2018). Front. Oncol. 8:179. doi: 10.3389/fonc.2018.00179

In the original article, the details for reference (70) were incorrect. The In Press version of the article was cited instead of the final published article. The full reference appears below. The authors apologize for this error and state that this does not change the scientific conclusions of the article in any way.

The original article has been updated.

\section{REFERENCES}

70. L’Abbate A, Tolomeo D, Cifola I, Severgnini M, Turchiano A, Augello B, et al. MYC-containing amplicons in acute myeloid leukemia: genomic structures, evolution, and transcriptional consequences. Leukemia (2018) doi: $10.1038 /$ s41375-018-0033-0

Conflict of Interest Statement: The authors declare that the research was conducted in the absence of any commercial or financial relationships that could be construed as a potential conflict of interest.

Copyright () 2018 Dragomir and Calin. This is an open-access article distributed under the terms of the Creative Commons Attribution License (CC BY). The use, distribution or reproduction in other forums is permitted, provided the original author(s) and the copyright owner(s) are credited and that the original publication in this journal is cited, in accordance with accepted academic practice. No use, distribution or reproduction is permitted which does not comply with these terms. 